\title{
ZONEAMENTO DOS AQÜÍFEROS DO ESTADO DA BAHIA
}

\author{
Maia, P. H. P. ${ }^{1}$ Cruz, M. J. M.. ${ }^{2}$ \& Sampaio, M. C. ${ }^{3}$ \\ 1. Instituto de Gestão das Águas e Clima. Av. Antônio Carlos Magalhães no 357, Itaigara, 41825-000 - \\ Salvador, BA - Brasil \\ 2. Universidade Federal da Bahia, Instituto de Geociências, Departamento de Geoquímica. Rua \\ Barão de Geremoabo S/N, Campus Ondina, 40170115 - Salvador, BA - Brasil \\ 3. Universidade Federal da Bahia, Instituto de Geociências. Rua Barão de Geremoabo S/N, Campus \\ Ondina40170115 - Salvador, BA - Brasil
}

\begin{abstract}
Maia, P. H. P.; Cruz, M. J. M.' \& Sampaio, M. C. 2009. Zoning of Aquifers the State of Bahia. Braz. J. Aquat. Sci. Technol. 13(1): 45-52. ISSN 1808-7035. The main objective of the research is to propose a zoning for the aquifers of Bahia state based on tectonic compartments, drainage patterns and directions of the main rivers of the state. The drainage is controlled by faults and fractures that result from various geological events. Assumption these structures that control the drainage are essential for accumulation and circulation of either surface water or groundwater. The result of this research was the emergence of large groups of aquifers in the State likely Hydrogeological Provinces and indication of different aquifer zones. The granular aquifers were divided into five provinces Hydrogeological with eleven different areas. The Karstic aquifers were targeted in eight provinces or areas Hydrogeological differentiated. The Metassedimentary aquifers were separated into nine distinct zones or units hydrogeological. And the Crystalline aquifers were divided into twenty-a Hydrogeological Provinces or areas aquifer from the analysis performed.
\end{abstract}

Keywords: zoning, aquifers, hydrogeological provinces

\section{INTRODUÇÃO}

O principal objetivo deste artigo é identificar e classificar os principais grupos de aqüíferos e propor um zoneamento, utilizando os compartimentos tectônicos, os padrões e a densidade de drenagem, juntamente com as direções preferenciais das fendas e fraturas que controlam a rede de drenagem. O pressuposto deste tema, é que as fendas e fraturas que controlam a rede de drenagem são fundamentais para a acumulação circulação da água, tanto em superfície quanto em subsuperfície, de acordo com o conceito de "riacho-fenda" amplamente utilizado na locação de poços em aqüíferos fissurais.

A elaboração do mapa hidrogeológico é a principal justificativa para identificar, classificar e zonear os grupos de aqüíferos do Estado para posteriormente caracterizar, por meio de estudos específicos, as unidades aqüíferas.

A concepção desse trabalho ocorreu a partir da observação da drenagem das bacias hidrográficas do Estado, na qual se destaca uma diversidade de padrões e áreas com densidade de drenagens diferenciadas, bem como, variações nas direções preferenciais dos rios.

O zoneamento também é de fundamental importância para avaliar, em cada área individualizada, as características hidrogeológicas e a densidade de fratu- ras, uma das variáveis a ser utilizada na determinação da vulnerabilidade intrínseca dos aqüíferos.

Densidade de drenagem

A densidade de drenagem se traduz como a relação entre o comprimento total dos cursos d'água de uma bacia hidrográfica e sua área. A estimativa da densidade de drenagem depende da escala carta topográfica uma vez que nas cartas de menor escala não são representados os pequenos cursos d'água, tampouco as bacias elementares.

A caracterização da densidade de drenagem como muito alta geralmente está relacionada a um substrato impermeável e de relevo acentuado e a muito baixa está relacionada a um substrato permeável de relevo suave. A densidade varia diretamente com a extensão do escoamento superficial e fornece uma indicação sobre a eficiência da drenagem natural da bacia, por exemplo, se a densidade é menor que $0,5 \mathrm{Km} /$ $\mathrm{Km}^{2}$, a bacia é mal drenada ${ }_{1}$ e densidade entre $0,5 \mathrm{e}$ $3,5 \mathrm{Km} / \mathrm{Km}^{2}$ é uma bacia bem drenada. As bacias com maior densidade de drenagem tendem a estar mais sujeitas a cheias e alagamentos do que as com menor densidade de drenagem.

A determinação da densidade de drenagem foi realizada em cada uma das áreas individualizadas neste trabalho, utilizando_ mapas e imagens de satélite em escala adequada. 

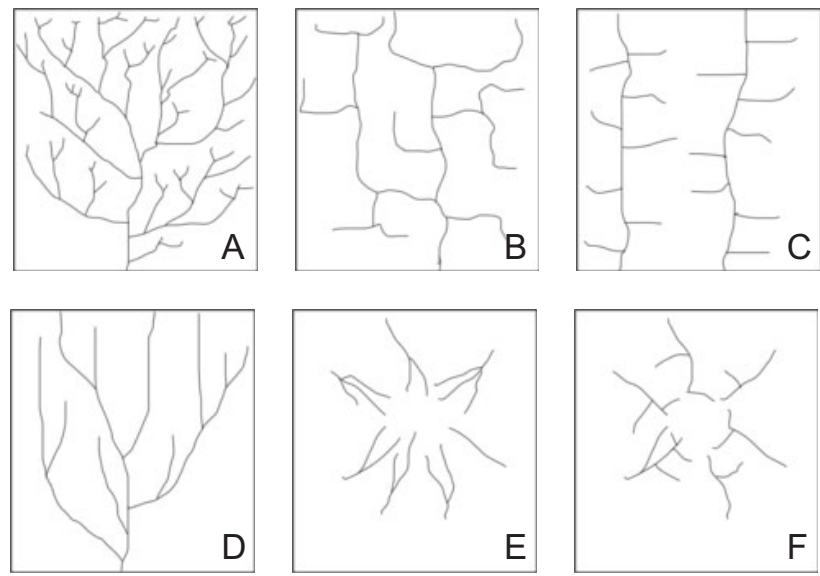

Figura 1. Principais padrões de drenagem: (A) Dendrítico; (B) Retangular; (C) Paralelo; (D) Treliça; (E) Radial; (F) Anelar.

\section{Padrões de drenagem}

Definidos como o arranjo espacial dos cursos de água em uma bacia hidrográfica, são condicionados pelo: controle estrutural, disposição das camadas, tipo litológico, declividade do terreno e evolução geomorfológica da região. Uma ou mais bacias hidrográficas podem ser englobadas na caracterização de uma área por um determinado padrão de drenagem. $\mathrm{Na}$ seqüência são definidos os principais padrões de drenagem (Figura 1).

\section{Dendrítico}

É típico de áreas cobertas por rochas horizontais não fraturadas e isotrópicas em relação à erosão. Constitui um padrão onde os talvegues têm comprimentos variados e não possuem nenhuma orientação preferencial. Comum em rochas sedimentares horizontais, podendo também ocorrer em rochas de baixo grau metamórfico, horizontais ou subhorizontais. Pode também ocorrer alguns derrames de lavas ou sedimentos de origem vulcânica.

\section{Retangular}

Os cursos d'água se encontram em ângulos retos. Ocorre em rochas que foram submetidas a processos de diaclasamento e falhamentos. A drenagem é condicionada pelas estruturas das rochas. Podem ocorrer em arenitos, derrames de lavas, rochas ígneas plutônicas, nas quais as diáclases se formam no processo de resfriamento. Comum também em rochas metamórficas submetidas a falhamentos e fraturamentos.

\section{Paralelo}

Padrão de drenagem onde os talvegues são paralelos a subparalelos entre si. Típico de regiões onde houve falhamento intenso em uma única direção ou em ca-

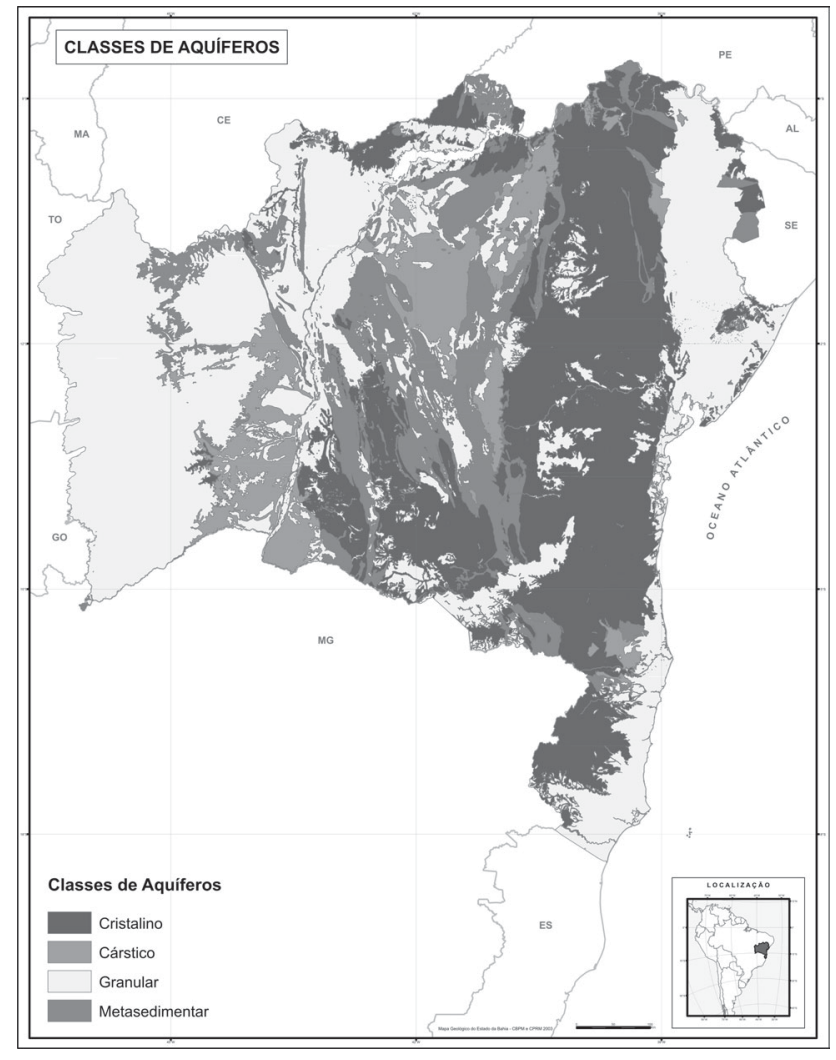

Figura 2 - Classes de Aqüíferos

madas sedimentares levemente inclinadas em regiões de topografia suave, onde os contatos geológicos se apresentam mais ou menos retilíneos.

\section{Treliça}

Padrão caracterizado pela existência de cursos d'água longos com um conjunto de tributários curtos que desembocam em ângulos retos no curso maior. É um padrão que se desenvolve em regiões dobradas, com uma sucessão de sinclinais e anticlinais de eixos horizontais a subhorizontais, onde os cursos maiores se encaixam em vales sinclinais e os cursos menores descem pelas abas das dobras.

\section{Radial}

Padrão caracterizado por talvegues que se dispõe radialmente a uma estrutura ou região mais elevada. Ocorre em estruturas vulcânicas, em áreas sedimentares soerguidas por domos salinos e em áreas onde afloram plutões ígneos que devido à erosão diferencial são realçados na topografia.

\section{Anelar}

Padrão caracterizado por drenagem radial na qual alguns cursos se colocam como segmentos de arcos ao redor de um ponto mais elevado a montante da drena- 
Tabela 01 - Aquíferos do estado da Bahia

\begin{tabular}{|c|c|c|c|c|c|c|}
\hline Unidade Geotectônica & Classe de Aquífero & $\begin{array}{l}\text { Tipo de } \\
\text { Porosidade }\end{array}$ & $\begin{array}{l}\text { Padrão de } \\
\text { Drenagem }\end{array}$ & $\begin{array}{l}\text { Densidade de } \\
\text { Drenagem }\end{array}$ & $\begin{array}{l}\text { Direção de } \\
\text { Drenagem }\end{array}$ & $\begin{array}{l}\text { Unidade } \\
\text { Aqüífera/Tectônica }\end{array}$ \\
\hline Coberturas Cenozóicas & Granulares & Intergranular & Dendrítico/Paralelo & Média /Baixa & NW-SE/E-W/N-S & Coberturas Cenozóicas \\
\hline 1a-Parnaíba & Granulares & Intergranular & Dendrítico/Paralelo & Média & NW-SE/SW-NE & Bacia do Parnaíba \\
\hline 1b-Urucuia & Granulares & Intergranular & Paralelo/Dendrítico & Baixa /Média & NW-SE/NE-SW & Bacia do Urucuia \\
\hline 1c-Recôncavo/Tucano & Granulares & Intergranular & Dendrítico/Paralelo & Baixa /Média & NW-SE/NE-SW & B.Recôncavo/Tucano \\
\hline 4a-São Francisco & Cárstico & Cárstico & Dendrítico/Paralelo & Baixa & NW-SE/NE-SW & São Francisco \\
\hline 4b-Una/Utinga & Cárstico & Cárstico & Dendrítico/Paralelo & Baixa & NW-SE/NE-SW/E-W & Una/Utinga \\
\hline 4c-Salitre & Cárstico & Cárstico & Dendrítico/Paralelo & Baixa & NW-SE/NE-SW/E-W & Salitre \\
\hline $4 d$-Irecê & Cárstico & Cárstico & Dendrítico/Paralelo & Baixa & NW-SE/NE-SW/E-W & Irecê \\
\hline 4e-Ituaçu & Cárstico & Cárstico & Dendrítico/Paralelo & Baixa & NW-SE/NE-SW/E-W & Ituaçu \\
\hline 6a-Pardo/Salobro & Cárstico & Cárstico & Dendrítico & Média/Alta & NW-SE/NE-SW & Pardo/Salobro \\
\hline 6b-Estância/Palmares & Cárstico & Cárstico & Dendrítico/Paralelo & Baixa & NW-SE/NE-SW/NNE & Estância/Palmares \\
\hline 7d-RioCuraçá & Cárstico & Cárstico & Dendrítico/Paralelo & Baixa & NW-SE/SE-NW/NNE & Rio Curaçá \\
\hline 2a-Rio Preto & Metassedimentar & Fissural & Dendrítico & Alta & NW-SE/NE-SW & Formosa do Rio Preto \\
\hline 2b-Santo Onofre & Metassedimentar & Fissural & Retangular/Paralelo & Alta & NNW/NNE/E-W & Santo Onofre \\
\hline 3-Espinhaço & Metassedimentar & Fissural & Retangular/Paralelo & Alta & NW-SE/NE-SW & Espinhaço \\
\hline 5-Chapada Diamantina & Metassedimentar & Fissural & Dendrítico/Paralelo & Média & NNW/NNE/E-W & Chapada Diamantina \\
\hline 7a-Riacho do Pontal & Metassedimentar & Fissural & Dendrítico/Paralelo & Média & NW-SE/NE-SW/NNE & Riacho do Pontal \\
\hline 7b-Riacho Tamboril & Metassedimentar & Fissural & Dendrítico & Baixa & NW-SE/NE-SW/NNE & Riacho Tamboril \\
\hline 7c-Barra bonita & Metassedimentar & Fissural & Dendrítico & Baixa & NW-SE/NE-SW/NNE & Barra Bonita \\
\hline 9b-Areião/Cont.-Mirante & Metassedimentar & Fissural & Paralelo/ Dendrítico & Média & NW-SE/E-W/N-S & Areião/Cont.-Mirante \\
\hline 7e-Faixa Sergipana & Metassedimentar & Fissural & Dendrítico & Alta & NW-SE/NE-SW & Faixa Sergipana \\
\hline 8a-Pernamb./Alagoas & Cristalino & Fissural & Paralelo/ Dendrítico & Média & NW-SE/NE-SW & Pernamb./Alagoas \\
\hline 8b-Canindé/Marrancó & Cristalino & Fissural & Dendrítico & Média & NW-SE/NE-SW & Canindé/Marrancó \\
\hline $8 \mathrm{c}$-Itapetinga & Cristalino & Fissural & Dendrítico & Média /Alta & NW-SE/NE/SW & Itapetinga \\
\hline 8d-Rio Preto & Cristalino & Fissural & Dendrítico & Média /Alta & NW-SE/NE-SW & Rio Preto \\
\hline 9a-Jacobina/Itapicuru & Cristalino & Fissural & Paralelo/ Dendrítico & Média & NW-SE/E-W & Jacobina/Itapicuru \\
\hline $12 \mathrm{~b}$-Salvador/Itabuna & Cristalino & Fissural & Retangular/Paralelo & Alta & NW-SE/NE-SW & Salvador/Itabuna \\
\hline 12c-Bloco de Jequié & Cristalino & Fissural & Paralelo/ Dendrítico & Alta & NW-SE/NE-SW & Jequié \\
\hline 13a-Bloco de Serrinha & Cristalino & Fissural & Paralelo/ Dendrítico & Alta & NW-SE/NE-SW/N-S & Serrinha \\
\hline 13b-Frag. de Mairi & Cristalino & Fissural & Dendrítico & Alta & NW-SE/NE-SW & Mairi \\
\hline 13c-Frag.de Barrinha & Cristalino & Fissural & Dendrítico & Média/Alta & NW-SE/NE-SW/N-S & Barrinha \\
\hline 14a-Bloc. Sobradinho & Cristalino & Fissural & Dendrítico/Paralelo & Alta & NW-SE/NE-SW & Sobradinho \\
\hline 14b-Bloc. Gavião & Cristalino & Fissural & Dendrítico/Paralelo & Média/Alta & NW-SE/NE-SW & Gavião \\
\hline 14c-Bloc. Paramirim & Cristalino & Fissural & Dendrítico/Paralelo & Média/Alta & NW-SE/NESW/NNW & Paramirim \\
\hline 14d-Bloc. Guanambi & Cristalino & Fissural & Dendrítico/Paralelo & Média/Alta & NW-SE/NESW/NNW & Guanambi \\
\hline 14e-Bloc. Lençóis & Cristalino & Fissural & Paralelo/ Dendrítico & Alta & NW-SE/NE-SW/N-S & Lençóis \\
\hline
\end{tabular}

gem radial. Muito comum em regiões que foram soerguidas por domos salinos ou intrusões ígneas. As fraturas são decorrentes da intrusão e soerguimento das rochas.

\section{MATERIAIS E MÉTODOS}

As unidades litológicas representadas no mapa geológico, na escala 1:1.000.000, foram classificadas em, com base na litologia, tipo de porosidade e comportamento hidrogeológico, em Classes de Aqüíferos: Granulares, Cársticos, Metassedimentares e Cristalinos que resultou em um mapa derivado, denominado de Classes de Aqüíferos (Figura 2).

Posteriormente, as informações espaciais contidas neste mapa foram superpostas com as poligonais que definem os principais compartimentos tectônicos, obtidas no Mapa Tectônico do Estado da Bahia (Figura 3) com o objetivo de delimitar as divisões regionais significativas dos aqüíferos. O resultado obtido foi um mapa contendo os recortes das prováveis Províncias Hidrogeológicas do Estado.

O mapa com essas poligonais foi utilizado como base, na qual foram lançadas a rede de drenagem de todas as bacias hidrográficas, obtida a partir da redução da base cartográfica na escala de 1:100.000, para caracterizar as Províncias Hidrogeológicas e identificar as zonas aqüíferas.

Em cada poligonal foram avaliados, os padrões, a densidade e as direções dos lineamentos da rede de drenagem, esses dados foram tabulados e tratados para permitir a indicação de zonas aqüíferas a serem investigadas em detalhe e confirmar sua validade posteriormente.

O resultado, expresso por meio de um Mapa de Zoneamento dos Aqüíferos do Estado da Bahia (Figura 4), propicia uma melhor visualização das zonas identificadas, nas quais os poços tubulares serão posteriormente plotados, e seus dados tratados com a finalidade de validar o zoneamento proposto.

Trata-se de um trabalho importante que irá contribuir para identificar, por meio de estudos, as principais Unidades Aqüíferas no contexto da elaboração do mapa hidrogeológico do Estado.

\section{RESULTADOS}

A sistematização adotada para classificar e organizar os aqüíferos do Estado foi planejada considerando os principais fatores que, direta ou indiretamente, interferem na acumulação e movimentação da água 


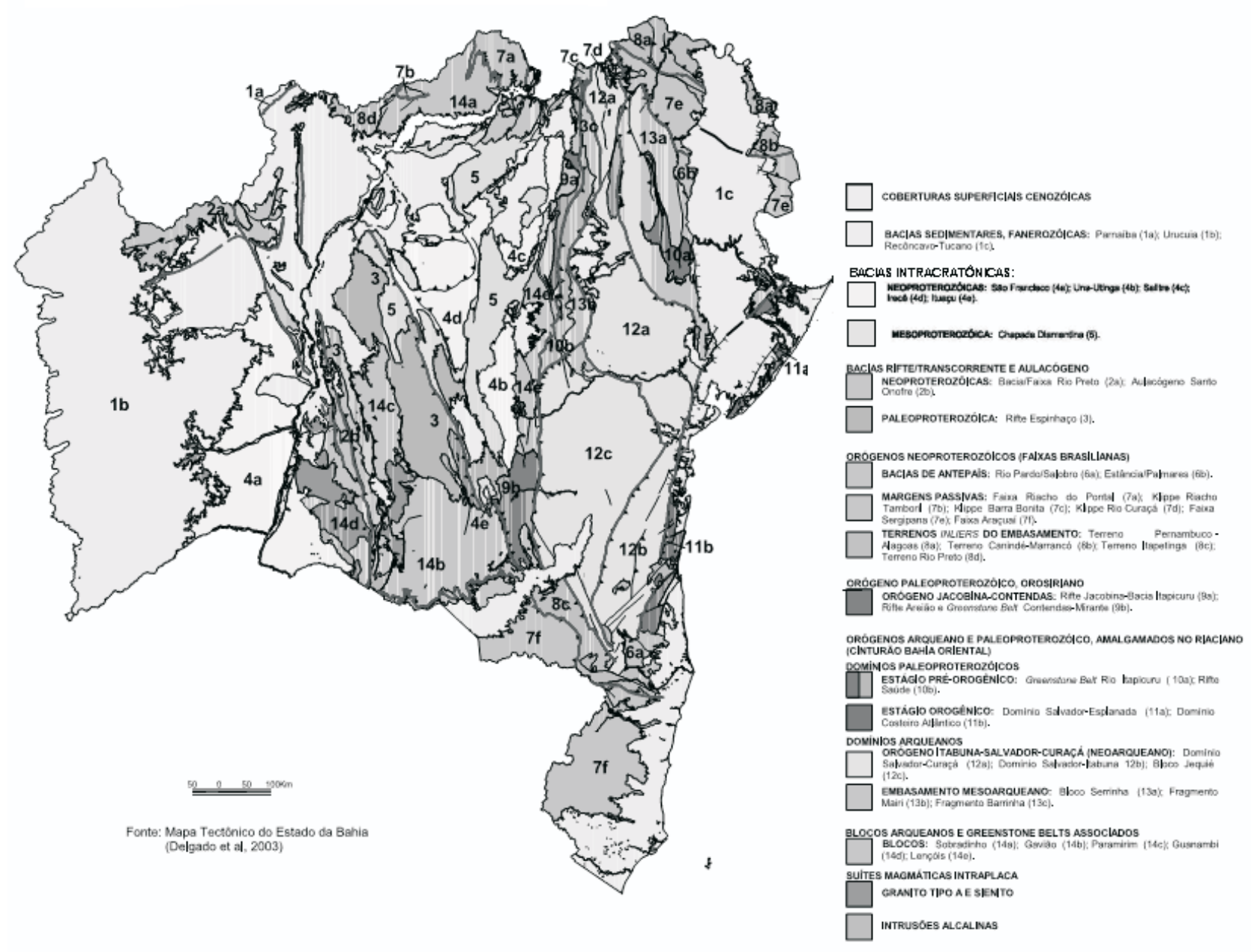

Figura 3 - Mapa Tectônico do Estado da Bahia

em subsuperfície, tais como: litologia, estruturas, tipos de porosidade e permeabilidade do substrato rochoso, declividade do terreno, evolução geomorfológica e geotectônica.

A investigação realizada aponta os caminhos para a individualização de unidades nas classes de aqüíferos: Granulares, Cársticos, Metassedimentares e Cristalinos. A identificação das prováveis Províncias Hidrogeológicas e a indicação de zonas diferenciadas na pesquisa encontram-se nas Tabelas 1 e 2.

\section{1 - Aqüíferos Granulares}

Os Aqüíferos Granulares abrangem as Coberturas Cenozóicas, as Bacias Sedimentares do Recôncavo, Tucano, Urucuia e Parnaíba, cuja pequena faixa da borda da bacia aflora próximo à cidade de Campo Alegre de Lurdes, na fronteira com o estado do Piauí.

Sob a denominação genérica de Coberturas Cenozóicas, este grupo engloba o aqüífero Barreiras, de grande importância regional que deve ser individualizado como uma unidade aqüífera independente que ocorre ao longo do litoral Atlântico, principalmente na região sul do estado, onde a densidade de drenagem é alta com uma freqüência acentuada do padrão de drenagem paralelo.

Essas coberturas ocorrem dispersas na região central do Estado, predominantemente no setor noroeste no Vale do rio São Francisco, onde áreas com baixa densidade de drenagem e padrão paralelo alternam-se com áreas de densidade média a alta e padrão de drenagem dendrítico, sugerindo a existência de zonas aqüíferas com características diferenciadas neste sistema.

As direções dos lineamentos da rede de drenagem nessas coberturas são variáveis a depender da unidade geotectônica que esteja recobrindo, denotando um forte controle estrutural do embasamento subjacente.

A bacia sedimentar do Recôncavo deverá ser objeto de uma análise detalhada, considerando a sua complexidade devido à ocorrência de várias unidades aqüíferas. A densidade de drenagem alta, o padrão dendrítico e as direções dos rios, individualizam esta 
Tabela 2- Zoneamento dos aqüíferos do estado da Bahia

\begin{tabular}{|c|c|c|c|}
\hline $\begin{array}{l}\text { Classes de } \\
\text { Aqüíferos }\end{array}$ & Porosidade & $\begin{array}{c}\text { Províncias } \\
\text { Hidrogeológicas }\end{array}$ & Zonas Aqüíferas \\
\hline \multirow{5}{*}{ Granulares } & \multirow{5}{*}{ Intergranular } & Coberturas Cenozóicas & $\begin{array}{l}\text { I- Barreiras } \\
\text { II- Depósitos Eólicos Continentais } \\
\text { III- Coberturas Superficiais }\end{array}$ \\
\hline & & Bacia do Parnaíba & $\begin{array}{l}\text { IV- Parnaiba } \\
\text { V- Urucuia Sul }\end{array}$ \\
\hline & & Bacia do Urucuia & $\begin{array}{l}\text { VI- Urucuia Central } \\
\text { VII- Urucuia Norte }\end{array}$ \\
\hline & & Bacia do Recôncavo & $\begin{array}{l}\text { VIII- Recôncavo } \\
\text { IX-Tucano }\end{array}$ \\
\hline & & Bacia do Tucano & $\begin{array}{l}\text { X- Tucano Sul } \\
\text { XI- Tucano Norte }\end{array}$ \\
\hline \multirow{8}{*}{ Cársticos } & \multirow{8}{*}{ Cárstica } & São Francisco & XII- São Francisco \\
\hline & & Utinga & XIII- Utinga \\
\hline & & Salitre & XIV-Salitre \\
\hline & & Irecê & XV- Irecê \\
\hline & & Ituaçú & XVI- Ituaçú \\
\hline & & Salobro & XVII- Salobro \\
\hline & & Estância & XVIII- Estância \\
\hline & & Rio Curaçá & XIX-Rio Curaçá \\
\hline \multirow{9}{*}{ Metassedimentares } & \multirow{9}{*}{ Fissural } & Formosa do Rio Preto & XX- Formosa do Rio Preto \\
\hline & & Santo Onofre & XXI- Santo Onofre \\
\hline & & Espinhaço & XXII- Espinhaço \\
\hline & & Chapada Diamantina & XXIII- Chapada Diamantina \\
\hline & & Riacho Pontal & XXIV- Riacho Pontal \\
\hline & & Riacho Tamboril & XXV- Riacho Tamboril \\
\hline & & Barra Bonita & XXVI- Barra Bonita \\
\hline & & Contendas Mirante & XXVII- Contendas Mirante \\
\hline & & Sergipana & XXVIII- Sergipana \\
\hline \multirow{21}{*}{ Cristalinos } & \multirow{21}{*}{ Fissural } & Araçuaí & XXIX-Araçuaí \\
\hline & & Alagoas & $\mathrm{XXX}$-Alagoas \\
\hline & & Canindé & XXXI- Canindé \\
\hline & & Itapetinga & XXXII- Itapetinga \\
\hline & & Rio Preto & XXXIII- Rio Preto \\
\hline & & Jacobina & XXXIV- Jacobina \\
\hline & & Rio Itapicuru & XXXV- Rio Itapicuru \\
\hline & & Saúde & XXXVI- Saúde \\
\hline & & Esplanada & XXXVII- Esplanada \\
\hline & & Costa Atlântica & XXXVIII- Costa Atlântica \\
\hline & & Curaçá & XXXIX- Curaçá \\
\hline & & Itabuna & $\mathrm{XL}$ - Itabuna \\
\hline & & Jequié & XLI- Jequié \\
\hline & & Serrinha & XLII- Serrinha \\
\hline & & Mairi & XLIII- Mairi \\
\hline & & Barrinha & XLIV- Barrinha \\
\hline & & Sobradinho & XLV- Sobradinho \\
\hline & & Gavião & XLVI- Gavião \\
\hline & & Paramirim & XLVII- Paramirim \\
\hline & & Guanambi & XLVIII- Guanambi \\
\hline & & Lençóis & XLIX- Lençóis \\
\hline
\end{tabular}

bacia como uma zona a parte, diferente da bacia do Tucano, na qual a baixa densidade da drenagem e a predominância do padrão de drenagem paralelo e secundariamente o dendrítico, juntamente com as direções dos lineamentos dos rios, sugerem a existência de pelo menos três compartimentos distintos: Uma zona a sul, outra na região central e a terceira localizada no norte da bacia.

A observação da drenagem na bacia do Urucuia permite visualizar um notável controle estrutural nos rios que sugere a existência de três zonas no aqüífero: uma onde o controle é mais acentuado, a sul, nas bacias dos rios Corrente e Itaguari, nas quais predomina um padrão de drenagem paralelo, outra na zona central, localizada no sul da bacia do rio Grande, na qual a drenagem passa de um padrão intermediário, entre o paralelo ao dendrítico, para um padrão dendrítico pleno, a norte da bacia sedimentar. A densidade de drenagem é baixa em toda a região e a direção predominante dos rios é WEE, com inflexões para SW-NE, na bacia do rio Grande e NW-SE, na bacia do rio Corren- te. Em ambos os casos os rios que correm na direção do rio São Francisco mudam abruptamente de direção.

\section{2 - Aqüíferos Cársticos}

Este sistema foi subdividido, com base nos compartimentos geotectônicos, litologia predominante (rochas carbonáticas) e porosidade cárstica, em oito unidades hidrogeológicas: São Francisco, Irecê, Salitre, Utinga, Ituaçu, Curaçá, Salobro e Estância. Excetuando o aqüífero Salobro que apresenta um padrão dendrítico e uma densidade de drenagem média a alta, nos demais aqüíferos prevalece o padrão dendrítico/ paralelo com densidade de drenagem baixa.

Quanto às direções dos lineamentos da drenagem, as unidades aqüíferas: Utinga, Salitre, Irecê e Ituaçu apresentam as mesmas direções preferenciais para NW-SE/NE-SW/E-W. Os aqüíferos São Francisco e Salobro apresentam as mesmas direções preferenciais para NW-SE/NE-SW, enquanto que nos aqüíferos, Estância e Curaçá as direções preferenciais são para NW-SE/ SE-NW/N-S. 


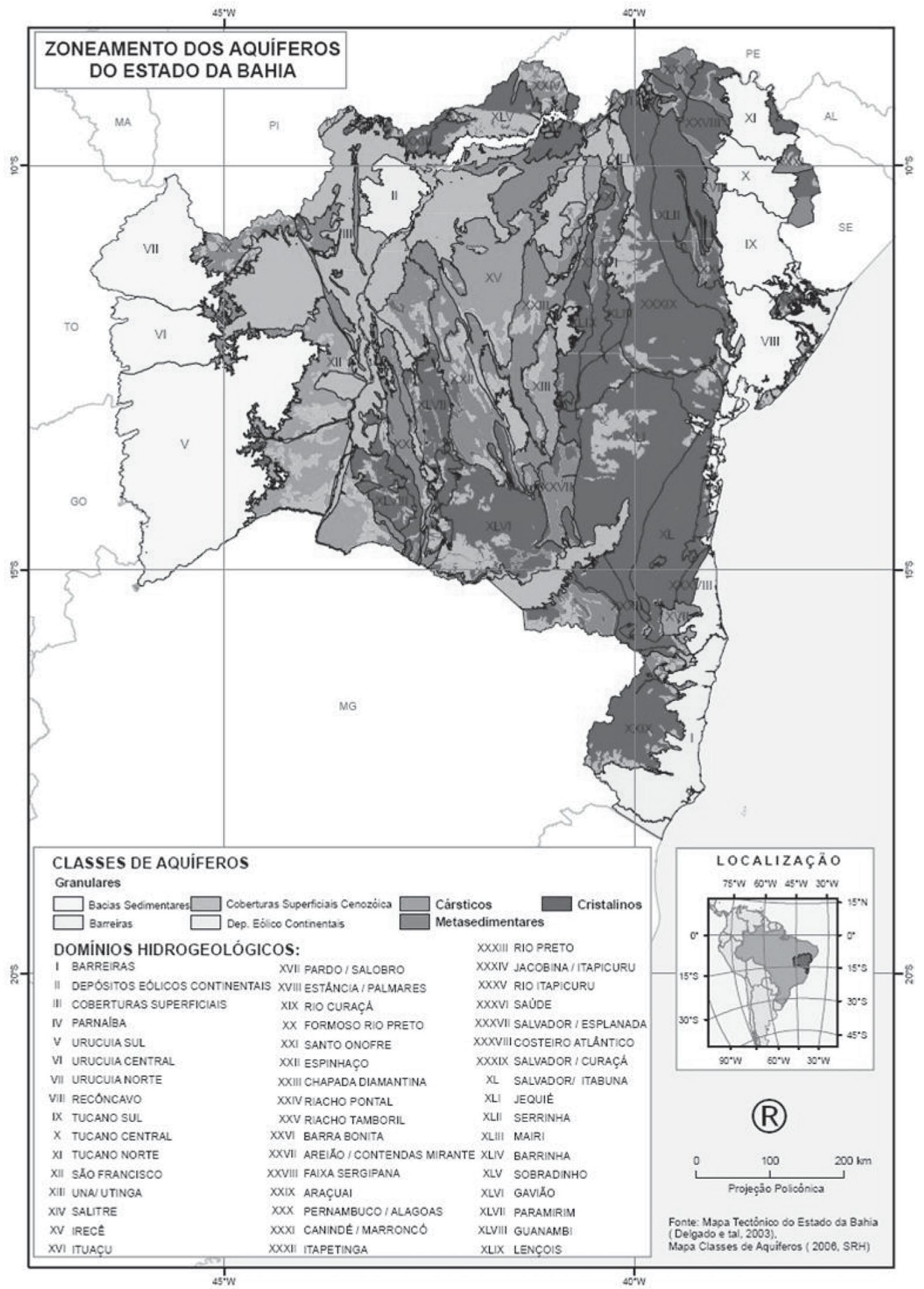

Figura 4 - Proposta de Zoneamento dos Aqüíferos do estado da Bahia 


\section{3 - Aqüíferos Metassedimentares}

Também com base nos compartimentos geotectônicos, litologia constituída por rochas metassedimentares e porosidade fissural este sistema foi segmentado em nove unidades hidrogeológicas: Formosa do Rio Preto, Santo Onofre, Espinhaço, Chapada Diamantina, Riacho do Pontal, Riacho Tamboril, Barra Bonita, Contendas Mirante e Sergipano.

Os padrões de drenagem dessas unidades variam de dendrítico, nos aqüíferos de Formosa do Rio Preto, Riacho Tamboril, Barra Bonita e o Sergipano a dendrítico/paralelo, com característica dos dois padrões, tais como Chapada Diamantina, Riacho Pontal e Contendas Mirante e retangular/paralelo, em áreas onde o controle estrutural sobre a drenagem é maior, como nos aqüíferos Santo Onofre e Espinhaço.

A densidade de drenagem também é predominantemente elevada, variando de alta e média, com exceção dos aqüíferos, Riacho Tamboril e Barra Bonita que apresentam uma densidade Baixa, provavelmente reflexo da permeabilidade do substrato, possível de ser confirmada com a análise estatística dos dados dos poços tubulares.

As unidades aqüíferas, Formosa do Rio Preto, Espinhaço e Sergipano apresentam lineamentos dos rios com direções para NW-SE/ NE-SW. As unidades Santo Onofre e Chapada Diamantina para as direções NNW/NNE/E-W. É notável a predominância dos lineamentos da rede de drenagem nas direções NW-SE/ NE-SW/NNE observadas nos aqüíferos de Riacho Pontal, Riacho Tamboril, Barra Bonita e Contendas Mirante .

\section{4 -Aqüíferos Cristalinos}

Este sistema deverá ser objeto de uma avaliação criteriosa para confirmar a sua segmentação em cerca de vinte e uma unidades aqüíferas, com base nos compartimentos geotectônicos, litologia e porosidade. Este zoneamento poderá ser confirmado por outros trabalhos complementares, tais como, análise da densidade de fraturas utilizando o sensoriamento e GIS e o tratamento estatístico dos dados dos poços.

Predominam os padrões de drenagem com características de dendrítico e paralelo, observado nas unidades: Alagoas, Jacobina, Rio Itapicuru, Saúde, Costa Atlântica, Jequié, Serrinha, Sobradinho, Gavião, Paramirim, Guanambi e Lençóis, seguida pelo padrão dendrítico pleno nas unidades: Araçuaí, Canindé, Itapetinga, Rio Preto, Esplanada, Curaçá, Mairí e Barrinha. A única unidade que apresentou um padrão retangular a paralelo, denotando um forte controle estrutural foi a unidade de Itabuna.

Das possíveis vinte e uma unidades hidrogeológicas identificadas, dezessete apresentam densidade de drenagem média a alta, apenas quatro delas, Alagoas, Canindé, Jacobina e Rio Itapicuru que possui densidade Média. Este resultado deverá ser comparado com a densidade de fraturas e com a análise estatística dos dados dos poços com a finalidade de confirmar a existência do zoneamento nessas áreas.

Com relação às direções dos lineamentos da rede drenagem, os esforços que afetaram esse sistema aqüífero produziram, em cerca de onze unidades: Alagoas, Canindé, Itapetinga, Rio Preto, Jacobina, Esplanada, Itabuna, Jequié, Mairí, Sobradinho e Gavião, lineamentos na drenagem, para as direções NWSE/ NE-SW. Secundariamente apresentam lineamentos, nas unidades: Rio Itapicuru, Saúde, Curaçá, Serrinha, Barrinha e Lençóis para NW-SE/ NE-SW/N$\mathrm{S}$. Nas unidades de Paramirim e Guanambi as direções preferenciais foram para NW-SE/ NE-SW/ N-S e as exceções ficam para Araçuaí e Costa Atlântica, a primeira com direções dos lineamentos NW-SE/ N-S e a segunda para NW-SE/NNE.

\section{CONCLUSÕES}

O resultado da pesquisa foi à segmentação dos grandes grupos de aqüíferos do Estado em prováveis Províncias Hidrogeológicas e a indicação de zonas aqüíferas diferenciadas, (tabela 2). Os aqüíferos Granulares, foram divididos em cinco Províncias Hidrogeológicas com onze zonas distintas. Os aqüíferos Cársticos foram segmentados em oito Províncias Hidrogeológicas ou zonas diferenciadas. Os aqüíferos Metassedimentares foram separados em nove Unidades Hidrogeológicas ou zonas distintas. E os aqüíferos Cristalinos foram divididos em vinte e uma Províncias Hidrogeológicas ou zonas aqüíferas, a partir da análise realizada.

O resultado, expresso por meio da Tabela 2 e de um Mapa de Zoneamento dos Aqüíferos do Estado da Bahia (Figura 4), propicia uma melhor visualização das zonas identificadas.

\section{REFERÊNCIAS BIBLIOGRÀFICAS}

Bigarella, J.J.; Suguio, K.; Becker, R.D. 1979. Ambiente Fluvial: Ambientes de Sedimentação, sua interpretação e importância. Editora da Universidade Federal do Paraná. Associação Defesa e Educação Ambiental, 183 p.

Christofolettl, A. 1981. Geomorfologia Fluvial, São Paulo.Editora Edgard Blücher, $313 \mathrm{p}$.

Christofoletti, A. 1980. Geomorfologia. São Paulo, Edgard Blücher, $2^{\mathrm{a}}$ ed. 
Cunha, S. \& Guerra, A. 1996. Geomorfologia - Exercícios, Técnicas e Aplicações. Editora Bertrand Brasil, S.A.

Delgado, I. M. in Dalton de Souza et al.; Mapa Geológico na escala 1:1.000.000. Convênio de Cooperação Técnico-Científica CBPM-CPRM, Salvador, Bahia, 2003.

Dias. L.S. 2005. Mapa das bacias Hidrográficas do Estado da Bahia, 1:1. 000.000, SRH - Superintendência de Recursos Hídricos do Estado da Bahia. Salvador-Ba.

Freitas, R.O. 1952. Textura de Drenagem e Sua Aplicação Geomorfológica. Boletim Paulista de Geografia. 11: 53-57.
Hung, L. Q.; Dinh N.Q.; Batelaan, O.; TAM, V. T. \& Lagrou, D.2002. Análise do Desenvolvimento de Cavernas Baseada em Sensoriamento Remoto e GIS na área de captação do Suoimuoi (Sun La - a NW do Vietnã). Jornal de Estudos de Cavernas e Carsts. 64: 23-33.
Submetido: Abril/2008

Revisado: Dezembro/2008

Aceito: Fevereiro/2009 